\title{
AMAMENTAÇÃO: UMA NECESSÁRIA MUDANÇA DE ENFOQUE *
}

\section{BREAST FEEDING: A NECESSARY FOCUS CHANGE}

Magda Andrade Rezende**

REZENDE, M.A. Amamentação: uma necessária mudança de enfoque.Rev.Esc.Enf.USP, v. 34, n. 2, p. 2269, jun. 2000.

\section{RESUMO}

Durante muitos anos o objetivo da produção científica sobre amamentação têm sido o produto: o leite. No entanto, pesquisas da década de 90, realizadas por enfermeiras, vêm mostrando que este enfoque não é adequado e que as nutrizes precisam ser vistas como pessoas que estão amamentando (ou tentando fazê-lo). O processo de amamentar pode ser muito sofrido causando, inclusive, desmame precoce. Tendo em vista tais interpretações, propõe-se um cuidado centrado na pessoa da nutriz. Deve-se lembrar também que a nutriz precisa de circunstância sócio-ambientais adequadas para conseguir amamentar e é dever da sociedade provê-las.

PALAVRAS-CHAVE: Aleitamento materno. Assistência centrada no paciente. Cuidados de enfermagem.

\begin{abstract}
During many years, the objective of the scientifc production on breast-feeding has been the product: milk. However, researches during the 90.s, performed by nurses, have shown that this focus is iatrogenic: milk becoming more important than people (the mothers in this case) and that the fortresses must be seen as persons who are breastfeeding (or trying to do so). The breast-feeding process can be very painful, also causing premature weaning. The author proposes, in view of these considerations, care that is centered on the person of the fortress. It must also be remembered that the fortress needs adequate social-ambient surroundings to achieve breast-feeding and it is society's duty to provide them.
\end{abstract}

KEYWORDS: Breastfeeding. Patient-centered care. Nursing care.

\section{INTRODUÇÃO}

No início da década de 80, trabalhando como enfermeira em uma unidade de internação neonatológica tive a oportunidade de ajudar muitas mães a amamentar. Nesta época minha percepção sobre a amamentação é de que era um "beneficio" para o bebê (e "até mesmo" para a mãe) e de que meu papel era ser o mais persuasiva possivel a fim de "convencer" as mães a amamentarem.

Foi neste contexto que participei de um encontro de enfermeiras de pediatria em 1981. Neste evento minha visão sobre amamentação se ampliou. Percebi que não se tratava apenas de uma ação de saúde. Era um comportamento social, e como tal deveria ser olhado, inclusive, através das ciências humanas. Apesar desta clareza, eu ainda não reunia condições suficientes para produzir um documento que demonstrasse tal ponto de vista. Assim, meu primeiro trabalho (BONILHA; REZENDE, 1982) não diferia de outros produzidos na mesma época, e dava um enfoque "utilitário" à mãe. Minha preocupação era fazer com que ela amamentasse a qualquer custo, em virtude dos "beneficios" para o bebê e ela.

Como se sabe, a Enfermagem profissional moderna se propõe a cuidar de um ser humano completo (SILVA, 1986; COLLIERE; 1989), e é com esta proposição que entramos em contato, tão logo nos tornamos alunos do curso de graduação. Ocorre que na execução deste objetivo muitas vezes somos reducionistas, focalizando apenas partes do cuidado ou da pessoa que está sendo atendida. Este reducionismo pode causar danos às pessoas que 
estão sob nossos cuidados. Esta forma utilitária de perceber a mãe contradiz nossa premissa de cuidar da pessoa como ser humano completo.

Já expus este ponto de vista ao comentar sobre o cuidado à criança em REZENDE (1998b). Cheguei a chamar de iatrogênico qualquer intento de cuidado que não considerasse a criança como centro, por estar falando de crianças especificamente, mas a idéia era (e é) considerar a pessoa como foco, seja qual for a circunstância.

Ora, é importante que a mãe seja vista como uma pessoa quer esteja amamentando ou não. Ver a mãe como pessoa é algo bastante recente na pesquisa em Enfermagem. Pode-se arrolar os seguintes trabalhos com esta postura. Cumpre salientar que trata de trabalhos isolados, embora tendo em comum a característica de terem sido realizados junto aos Programas de Pós-Graduação em Enfermagem da Universidade de São Paulo, tanto em nivel de Mestrado, quanto de Doutorado.

ARANTES (1991), para sua dissertação de Mestrado, entrevistou mulheres funcionárias de faculdades da USP de Ribeirão Preto, nos anos de 1989 e 1990 buscando perceber como estas mães viveram a amamentação. Descobriu que esta foi eventualmente uma vivência sofrida e desagradável. Várias mães haviam se sentido culpadas por não terem conseguido amamentar e falaram de sua sensação de desamparo ao sair da maternidade. Queixavam-se de sua dor por não terem sido compreendidas e, o que é pior, por terem sido julgadas pelos profissionais de saúde que as estavam atendendo no caso de não estarem conseguindo amamentar.

A pesquisadora SILVA (1994), em sua tese de Doutorado, propôs-se a compreender o amamentar sob a ótica da nutriz. Coletando dados junto à mulheres que moravam em uma favela da cidade de São Paulo, em 1992 e 1993, descobriu que o fenômeno central da amamentação para aquelas pessoas consistia em "pesar riscos e beneficios". "A mulher se encontra em constante processo dialético envolvendo avaliação e estimativa dos símbolos identificados na sua experiência de amamentar" (p.177). Deste modo ela define a situação de amamentar para si passando a representá-la em termos simbólicos de riscos e beneficios e é assim que toma as decisões neste campo.

Em sua tese, NAKANO (1996), por sua vez, analisou a situação de mulheres que estavam amamentando pela primeira vez (o que não significa que fossem primiparas. A pesquisa foi realizada na cidade de Ribeirão Preto (SP) com mulheres que freqüentavam uma Unidade Básica de Saúde-UBS, cujos bebês tivessem, no momento da entrevista, idade entre um e 12 meses. A autora constatou que a amamentação "se configura como qualificador do ser mãe".

JAVORSKI (1997), para sua dissertação, entrevistou na cidade de Recife, PE, mães cujos filhos estavam internados em unidade de Cuidado Canguru*, visando compreender a situação de amamentar uma criança pré-termo. As mães, afirma a autora, vivem conflitos e contradições, pois sabem que a amamentação é importante para a saúde de sua criança, mas não contam com apoio suficiente para manter a lactação. Precisamos perceber "que essas mulheres não são abstratas, mas estão inseridas em contextos sociais concretos" (p.147).

Minha própria tese de doutorado (REZENDE, 1998a) foi construida tendo em mente este enfoque e possibilitou conhecer vivências de nove mães que trabalhavam na Escola de Enfermagem da Universidade de São Paulo e que tiveram filhos entre agosto de 1993 e agosto de 1997. Destas, seis eram enfermeiras docentes e três funcionárias de serviços administrativos. As condições sócio-econômicas destas mães, bem como sua organização de trabalho eram diferentes.

Foi percebido que mães enfermeiras, no caso de sua primeira maternidade, vivem uma situação angustiante em termos de amamentação, pois cobram de si mesmas elevados padrões de desempenho. As que estão vivendo a maternidade pela segunda vez não vivem situação tão angustiante, embora os primeiros meses após o nascimento do bebê sejam uma fase igualmente exaustiva. Mas, de qualquer modo, estas também percebem a amamentação como parte da maternidade, e o mesmo é depreendido dos discursos das três mães não-docentes.

Para tais mães, portanto, amamentação está intimamente associada à maternidade tal como foi mostrado por ARANTES (1991), NAKANO (1996) e JAVORSKI (1997).

Estas pesquisas, nas quais as autoras tiveram por objetivo conhecer as experiências de acordo com as próprias mães, permitiram evidenciar a complexidade do processo de amamentar. Em meu trabalho (REZENDE, 1998a), por exemplo, em várias situações é evidente que a nutriz precisa de ajuda para se organizar e tranqüilizar e, assim, amamentar. Por exemplo: ao retornar para casa após o parto e se perceber sozinha para cuidar de uma série de tarefas, ou, ao retornar ao trabalho remunerado quando a licença termina.

\footnotetext{
* Cuidado Canguru "consiste em colocar o bebê prematuro em posição supina junto à pele entre os seios da mãe sustentado por uma faixa de tecido semelhante a uma bolsa, que é amarada em torno do tórax da mulher. (...) O contato íntimo do bebê com o corpo materna ajuda na regulação da temperatura corporal da criança, na promoção do aleitamento materno e pode facilitar o apego entre mão e filho" (JAVORŞKI, 1997, p.54)
} 
Ter que enfrentar uma seqüência ininterrupta de situações que exigem intervenção imediata, ao longo de meses e, muitas vezes, sem qualquer tipo de ajuda mostram-nos isto e nos remetem a uma conclusão: a mulher precisa ser vista como uma pessoa e não como um peito que amamenta. Para o profissional de saúde é uma mudança radical em termos de proposta de atuação mas, finalmente é o encaminhamento concreto de nossa proposta holística de cuidado (SILVA, 1986; COLIIERE, 1989). Chegar-se a tais pesquisas, no entanto, foi possivel porque o olhar das pesquisadoras o permitiu. Foi um olhar baseado na perspectiva do sujeito e de compreensão de sua perspectiva. Neste sentido insere-se nas abordagens humanistas, dentre as quais podemos citar a de ROGERS (1983; 1991). No entanto, somente ter a perspectiva do outro como sujeito não teria sido suficiente. Era necessário usar-se um desenho metodológico que permitisse a apreensão daquela visão de mundo e isto foi suprido com o uso de abordagens qualitativas de pesquisa .Tais trabalhos, portanto, devem-se a esta confluência feliz: de perspectiva profissional e disponibilidade de metodologia adequada.

Estes trabalhos permitiram que eu propusesse três pontos que considero premissas basilares no trabalho com a mulher que está vivendo a situação de amamentar, que está tentando ou mesmo que não tenha conseguido fazê-lo:

1. A mulher é uma pessoa, e como tal deve ser cuidada, isto é, preservando-se e fortalecendo-se sua capacidade de decidir, que em suma é a primeira premissa exposta de modo concreto. Cuidar da mulher como pessoa significa fazê-lo tendo um parâmetro humano, tal como advogado por ROGERS (1983, 1991). Na situação específica com a qual estamos lidando - a de amamentação isto significa dar à mãe todas as informações possiveis sobre amamentação e ajudá-la durante todo o processo, sem nunca julgá-la tendo sempre em mente que cada uma das mães têm peculiaridades que a tornam única.

2. A mulher é a pessoa central no processo de amamentar. Como tal deve ser tratada pelo profissional de saúde.

3. A mulher precisa de circunstâncias sócioambientais adequadas para conseguir amamentar e é dever da sociedade provêlos. Trata-se, basicamente, das condições de que necessita como trabalhadora, mãe e nutriz.

A respeito desta última lembrou GRANT (1984), ex-diretor executivo do Fundo das Nações Unidas para a Infância-UNICEF, por ocasião do lançamento do Programa Nacional de Incentivo ao Aleitamento Materno:
"Promover a causa do aleitamento materno é promover a disponibilidade das mães para amamentar seus filhos, várias vezes por dia, todos os dias de cada mês, por um ano ou mais, e fazêlo no caso de vários filhos durante vários anos. Ignorar este fato seria transformar a campanha de incentivo ao aleitamento materno noutro exemplo de pressões sociais, para aumentar as aspirações da mulher. sem oferecerlhe o minimo de apoio. Por isso, esta campanha deve também preocupar-se com a questão da licença remunerada para a maternidade; da segurança contratual durante a gestação e parto; da instalação de creches e de locais adequados para o aleitamento materno no trabalho; dos intervalos remunerados para a amamentação; de tecnologias para aliviar a carga de trabalho feminino; de educação comunitária sobre os processos de gestação, lactação e desmame, e das

mudanças nos procedimentos
hospitalares." (Grifo meu).

Grant não foi o único a lembrar que as condições sociais são indispensáveis quando se pensa em promover amamentação. MARTINS FILHO (1985), VINHA (1984) e eu mesma (REZENDE, 1986) também o fizemos, bem como ORLANDI (1985), embora ele tenha sido mais contundente:

"uma campanha de incentivo ao aleitamento materno, -sem a concomitante criação de condições para que isso se efetive, vai apenas provocar um brutal sentimento de culpa em mães impotentes para solucionar um problema do qual são, mais que tudo, vitimas."

Portanto, condições ambientais juntamente com uma abordagem baseada em interações humanas, são, no meu entender, condições indispensáveis para amamentação.

\section{REFERÊNCIAS BIBLIOGRÁFICAS}

ARANTES, C.I.S. O fenômeno amamentação: uma proposta compreensiva. São Paulo, 1991. 86p. Dissertação (Mestrado) Escola de Enfermagem de Ribeirão Preto, Universidade de São Paulo.

BONILHA, A . L. de L.; REZENDE, M.A . Atuação do enfermeiro no processo de preparo para o aleitamento natural e sua manutenção e de relactação. São Paulo, 1982. 96p. Monografia (Curso de Especialização em Enfermagem Pediátrica e Puericultura) - Escola Paulista de Medicina. 
COLLIĖRE, M.F. Promover a vida: da prática das mulheres de virtude aos cuidados de enfermagem. Lisboa, Sindicato dos Enfermeiros Portugueses, 1989.

GRANT, J. Situação mundial da infância - 1984. Brasília, UNICEF, 1984.

JAVORSKI, M. Os significados do aleitamento materno para mães de prematuros em cuidado canguru. Ribeirão Preto, 1997. 177p. Dissertação (Mestrado) - Escola de Enfermagem de Ribeirão Preto, Universidade de São Paulo.

MARTINS FILHO, J. Como e porque amamentar. São Paulo, Sarvier, 1984.

NAKANO, A . M. S. O aleitamento materno no cotidiano feminino. Ribeirão Preto, 1996. 170p. Tese (Doutorado) - Escola de Enfermagem de Ribeirão Preto, Universidade de São Paulo.

ORLANDI, O. Teoria e prática do amor à criança: introdução à pediatria social no Brasil. Rio de Janeiro, Jorge Zahar, 1985.

REZENDE, M.A. Aleitamento materno: influência dos meios rural e urbano. Rev.Cult Vozes, v.80, n.4, p.245-52, 1986.
Amamentação e trabalho na escola de enfermagem da Universidade de São Paulo: um estudo sobre representações sociais. São Paulo, 1998a. 194p. Tese (Doutorado) - Escola de Enfermagem, Universidade de São Paulo.

A valorização do ser humano criança como referencial na prevenção de iatrogenias. O mundo da saúde. v.22, n.6, p.341-3. 1998b.

ROGERS, C. Um jeito de ser. São Paulo, EPU, 1983. 1991.

SILVA, G.B. da Enfermagem profissional: análise crítica. São Paulo, Cortez, 1986.

SILVA, I.A. Amamentar: uma questão de assumir riscos ou garantir beneficios. São Paulo, 1994. 198p. Tese (Doutorado) Escola de Enfermagem, Universidade de São Paulo.

VINHA, V.H.P. Amamentação materna: incentivo e cuidados. São Paulo, Sarvier, 19 